\title{
Examining Performance of Geometrical Thinking in Mathematics at Secondary School Level in Pakistan
}

\author{
Amir Zaman ${ }^{*}$ \\ Abdul Ghafar** \\ Fazal ur Rahman ${ }^{* * *}$ \\ Ishtiaq Hussain $^{* * * *}$
}

\begin{abstract}
Geometrical thinking is important for students to perform well in mathematics as a whole. This study aimed at assessing performance of grade 9th students in Geometrical thinking. Furthermore, comparison among students in different strata was made like sector wise, gender wise and location wise. A test of reasoning was administered to a sample of above 500 hundred. Sample of the study was taken with proportionate approach from the whole population. The test was properly validated and reliably checked using SPSS. Factor analysis of the test shows that all items were statistically aligned with theoretical model. The results show that the students perform in a variety of ways like performance of private schools students was significantly better than students of public schools. Similarly, male and urban students performed well than female and rural students respectively. However, the difference between score of the students in private and public schools were found significant. Interaction analysis of gender, rural urban divide shows; that some items show interaction effect by behaving differently in response to background variables. It was recommended for further research to replicated this study on different level with tools suitable for their level and also can be better conducted using tools that involve diagrammatic reasoning.
\end{abstract}

Keywords: geometrical thinking, mathematics achievement, mathematical thinking

\footnotetext{
* Associate Professor, Abdul Wali Khan University Mardan. ${ }_{* * *}^{* *}$ Associate Professor, Abdul Wali Khan University Mardan. *** Associate Professor, Allama Iqbal Open University, Islamabad. Email: fazalaiou@yahoo.com

**** Ishtiaq Hussain, Associate Professor, Kohat University of Science and Technology Email: dr.ishtiaq@kust.edu.pk
} 


\section{Introduction}

Unfortunately the system of education in Pakistan is focusing on student's grade rather than students thinking skills. Among the school subjects, mathematics is considered to be the most boring subject. It is far from reality that mathematics is not interesting, however, it depends on how it is being taught and the teaching methods adopted into practice in Pakistan (Rania, 2017). Students, consequently, develop negative attitude towards mathematics and learning of mathematics. This attitudinal factor affects students' outcomes in mathematics.

Devlin (2001) viewed mathematics a combination of a systematic organization and arrangement of patterns which are rationally connected. Mathematics students are required to learn and develop their reasoning ability with Geometrical approach. It not only is required of mathematics students but students from other disciplines as well (Frances, 1995).

Proofs support the claims of mathematics as opined by Nyaumwe and Buzuzi (2007, p.2) "it is not more than a subject for which feasibility of claims is uncertain till these claims are proved. It can be just assumed and may not be taken for granted".

The science of mathematics is separated from other empirical sciences with solid proofs (Milton \& Reeve, 2003). It is pivotal for mathematical activities to be supported by relevant proofs (Porteous, 1990). NCTM (2000) states about the importance of mathematical proofs as follow, "Reasoning and proofs must be viewed as basic components of mathematics; frame and investigate mathematical conjectures; build up appraise its arguments and proofs; selection and usage of various reasoning types and proofs is obligatory.

Feasibility of mathematical assumptions are proved or refuted after following Geometrical steps with confirmed output results (Brumbaugh \& Rock, 2001). Hanna (1996) sees mathematical proofs from a pedagogical point of view which should crystal clear by using information and rules of reasoning for verification or falsification of the results, these needs to be very clear and open to criticism. Conjecture is either false of viable which is beyond any doubt. Proofs do not only support results as true but it is inclusive to social construction of these results as well. It is important for students to enhance their understanding of the knowledge of mathematics subject with learner centred class room (Wheatley, 1992).

Mathematical proofs are structural and systematic discourses which follow a step wise approach to arrive at a solid conclusion by comprehensive acceptable standards of the field. The aims of proof are not only limited to verification of facts but getting an understanding of the effective ways pertaining to information than memorization. 
Proofs regarding mathematic into the canvas of man activity needs not only an understanding of the definitions but also logical procedures to be questioned as how and why? (Tall, p.506). Proofs at its broader spectrum try to communicate the conviction and verification of results to others (Bell, 1976).

Hanna (1996) argues that now a days mathematical experimentation specifically student-centred classrooms have led to accept the viability of mathematical assumptions as being accurate or otherwise. It can be concluded that valid proofs geometrical reasoning, systematic approach and critical thinking are central to the subject of mathematics.

In their revised work Principles and Standards for School Mathematics (2000) the NCTM states that "Geometry has long been regarded as the place in the school mathematics curriculum where students learn to reason and to see the axiomatic structure of mathematics" (p. 40), and that "Geometry offers a means of describing, analyzing, and understanding the world and seeing beauty in its structures" (p. 309). Supporting their 1989 statement that geometry was useful for the learning of other branches of mathematics and problem solving, the NCTM further stated in 2000 "Geometric ideas can be useful in other areas of mathematics and in applied settings" (p. 309).This section summarized the studies which are focused on gender comparison on mathematical thinking with relationship of geometry, proofs and spatial reasoning. The goals of proof are not the mere verification of truth but the gaining of understanding by using of formal logic. Proofs in geometry allow one to logically argue from known information to the unknown facts which, eventually, help students to deduce logically in practical life.

Many researchers have reported better performance of boys over girls e.g. Bessoondyal (2005) studied the gender difference in mathematics in Mauritius including the strand of geometry as well and and reported the boys performed significantly better than girls in overall test, also in separate strands of the test boys outperformed girls in geometry. Battista (1990) conducted a study concerned with the spatial and geometrical thinking of students. A sample of 145 high school geometry students both male and female were tested in four areas; spatial visualization, logical reasoning, geometrical knowledge, and geometrical problem solving. Battista (1990) found that males scored significantly higher than females on geometrical knowledge and geometrical problem solving. However, his study was more concerned with measuring achievement in geometry in terms of comprehension of basic concepts, techniques, and principles and the ability to apply understanding to new situations instead of proofs. El-Hassan (2001) in Lebanon found that, at the 13 grade in operation and geometry topics, males performed better 
than females. Ma (1995) conducted a study on a sample of 960 students from both senior and junior classes in four countries namely British Columbia, Ontario, Hong Kong, and Japan. The aim of the study was investigate gender difference across different education system in domain of algebra and geometry. The study used data from the Second International Mathematics and Science Study (SIMSS) and reported a significant gender differences among senior students where males students outperformed females on the geometry subtest.

In contrast some studies have found that girls are performing well in geometry e.g. Mamoon (2005) as discussed earlier found that females had significantly higher scores than males for subtest of Mathematical proof in his test of mathematical thinking. TIMSS (2007) study which was undertaken in 59 countries for grade 4 and 8 students in target content areas in mathematics for grade 4 were number, geometric shapes and measures, data display and for grade 8 number, algebra, geometry, data and chance. It is reported for both grades that girls had higher achievement on average in geometry. Girls had higher achievement in 15 countries and boys in 6 countries. Healy and Hoyles (2000) conducted a study on Proof conceptions in Algebra by surveying high-attaining 14 and 15-year-old students and concluded that gender of the students was significantly associated with achievement where girls obtained higher scores than boys in construction of proofs.In TIMSS (2003) Jordanian females had a significantly higher average score than males consistent with seven other countries in geometry.

Senk and Usiskin (1983) conducted a study on large sample of 2699 in 99 different classes to investigate any gender differences in the understanding on geometrical proof for senior high students ranging from 7 grades to 12 grades. Three forms of a proof test were devised so that performance on a greater number of proofs could be analyzed. The students were tested on their knowledge of geometry at the beginning of the year and their understanding of three types of standard geometry proofs at the end of the year. They found that though boys had a slight higher score but no consistent pattern of statistically significant differences favoring either sex on any form of proof tests was found. Huntley (1990), in his study regarding effect of diagram formats on performance on geometry items administered a 32 experimental, multiple-choice geometry items were administered in two pretest versions; one version did and one version did not provide a relevant diagram. Log linear analysis of the data shows that there were no significant differences between males and females students' performance on these items.

Literature review shows that there is no single direction regarding gender differences in the performance of students in geometry. Some studies support the superior performance of male over female in 
geometry and mathematical proofs (Battista, 1990; Bessoondyal, 2005; El-Hassan, 2001; Ma', 1995) while some other report better performance in geometry by female students or no difference (Mamoon, 2005; TIMSS, 2007; TIMSS, 2003; Senk \& Usiskin,1983; Huntely, 1990 ).

\section{Methodology}

The study used survey approach and population for the study was 371000 students enrolled in 2703 secondary schools at grade 9 level.

\section{Sample for the Study}

A multi staged probability sampling techniques was used to draw sample from population for quantitative data collection. Total sample for the survey was decided to be 500 subjects or beyond. Proportionate approach in sampling was adopted as illustrated in the table 1 given below.

Table 1

Composition of the Sample

\begin{tabular}{lccccll}
\hline & \multicolumn{2}{c}{ Sector Wise } & \multicolumn{2}{c}{ Gender Wise } & \multicolumn{2}{l}{ Location Wise } \\
\hline & Public & Private & Male & Female & Rural & Urban \\
Percent & 50 & 50 & 70 & 30 & 70 & 30 \\
Number of & 289 & 289 & 405 & 173 & 405 & 173 \\
Students in sample & & & & & & \\
\hline
\end{tabular}

\section{Tool}

An extended response items test was developed that focused on reasoning about geometrical proofs. Content validity was ensured through expert opinion and construct validity was checked through factor analysis. Reliability of the instrument was found to be 0.90 .scale wise reliability is given in table 2

Table 2

Item Wise Reliabilities Analysis for Test of Mathematical Thinking

\begin{tabular}{ccc}
\hline Item & Scale Mean if Item Deleted & $\begin{array}{c}\text { Cronbach's Alpha if Item } \\
\text { Deleted }\end{array}$ \\
\hline G1 & 0.22 & 0.78 \\
G2 & 0.21 & $\mathbf{0 . 7 3}$ \\
G3 & 0.18 & 0.74 \\
G4 & 0.19 & 0.70 \\
G5 & 0.46 & 0.75 \\
G6 & 0.29 & 0.71 \\
\hline
\end{tabular}


Table 2 shows that all individual items had good reliability value above 0.70 therefore all items were retained for the study.

\section{Analysis}

$t$-test was used to make gender comparison in Geometrical thinking. Table 3 below shows the results of analysis

Table 3

Gender Wise Comparison of Geometrical Thinking

\begin{tabular}{cccccccc}
\hline & \multicolumn{2}{c}{$\begin{array}{c}\text { Male } \\
\text { Mean Std. } \\
\text { Scale }\end{array}$} & \multicolumn{2}{c}{$\begin{array}{c}\text { Female } \\
\text { Mean Std. } \\
\text { Deviation }\end{array}$} & $t$-value & $\begin{array}{c}\text { Sig.(2- } \\
\text { tailed) }\end{array}$ & $\begin{array}{c}\text { Effect size } \\
\text { Cohen's d }\end{array}$ \\
\hline $\begin{array}{l}\text { Geometrical } \\
\text { thinking }\end{array}$ & 9.95 & 6.597 & $9.37 \quad 4.518$ & .887 & 0.377 & 0.102 \\
\hline
\end{tabular}

* Mean difference is significant at $P<0.05$

** Mean difference is significant at $P<0.01$

Above table shows that male students have better mean in the test for geometrical thinking than their female counter parts, however this difference in mean was not significant. To evaluate mean difference in mean score effect size was calculated using Cohen's D effect size. Cohen's d value shows that effect size was found to be small in case of Geometrical thinking (Cohen, 88).

Similarly urban and rural students' mean scores in test of geometrical thinking was compared for significant difference in their mean score using sampled paired t-test. The results are shown in table 4 indicating that urban students mean score was better than rural students in geometrical thinking however the difference was not significant.

Table 4

Location Wise Comparison of Geometrical Thinking

\begin{tabular}{|c|c|c|c|c|c|c|c|}
\hline Scales & $\begin{array}{l}\text { Urban } \\
\text { Mean }\end{array}$ & Std. Dev & $\begin{array}{l}\text { Rural } \\
\text { Mean }\end{array}$ & Std. Dev. & $\begin{array}{l}t \text { - } \\
\text { value }\end{array}$ & $\begin{array}{l}\text { Sig. } \\
(2- \\
\text { tailed) }\end{array}$ & $\begin{array}{l}\text { Effect size } \\
\text { Cohen's D }\end{array}$ \\
\hline $\begin{array}{l}\text { Geometrical } \\
\text { thinking }\end{array}$ & 9.37 & 4.845 & 8.05 & 6.671 & $\begin{array}{c}- \\
1.887\end{array}$ & .061 & 0.23 \\
\hline
\end{tabular}

* Mean difference is significant at $P<0.05$

** Mean difference is significant at $P<0.01$

To further elaborates the amount of the difference Cohen's D effect size was also calculated and table 4 shows a small effect size (Cohen, 88) 
in Geometrical thinking. Urban students mean score in Geometrical thinking was 9.37 respectively as compared to 8.05 for the same scale respectively by rural students.

Similar comparison was made among different sectors of the schools i.e. private and public sector

Table 5

Sector Wise Analysis of Geometrical Thinking

\begin{tabular}{|c|c|c|c|c|c|c|}
\hline \multirow[b]{2}{*}{ Scale } & Public & \multicolumn{2}{|c|}{ Private } & \multirow[b]{2}{*}{$t$-value } & \multirow{2}{*}{$\begin{array}{l}\text { Sig.(2- } \\
\text { tailed) }\end{array}$} & \multirow{2}{*}{$\begin{array}{l}\text { Effect size } \\
\text { Cohen's d }\end{array}$} \\
\hline & $\begin{array}{l}\text { Std. } \\
\text { Deviation }\end{array}$ & Mean & $\begin{array}{l}\text { Std. } \\
\text { Deviation }\end{array}$ & & & \\
\hline $\begin{array}{l}\text { Geometrical } 6.00 \\
\text { thinking }\end{array}$ & 4.746 & 11.05 & 5.553 & 11.526 & $0.000 * *$ & 0.98 \\
\hline
\end{tabular}

Table 5 shows that private students' mean score was better than public students in Geometrical thinking. Cohen's D value shows that effect size is small for Geometrical thinking (Cohen, 88). Private sectors' students' mean score in Geometrical thinking was 11.05 as compared to scores of 06.0 for the same scale respectively by female students. Table 6 shows that Eta squared values of interaction effect between gender and location for Geometrical thinking, 0.000 which shows significant results in favor of female students. This result may be due to the fact that girls have more tendency towards drawings and like to play with figures,

Table 6

Interaction Effect between sector and Location

\begin{tabular}{|c|c|c|}
\hline $\begin{array}{l}\text { Sector } \\
\text { Eta }^{2}\end{array}$ & $\begin{array}{l}\text { Location } \\
\text { Eta }^{2}\end{array}$ & $\begin{array}{l}\text { Location \& Gender } \\
\text { Eta }^{2}\end{array}$ \\
\hline Geometrical thinking & .000 & .001 \\
\hline \multicolumn{3}{|l|}{$*$ Difference is significant at $P<.05$} \\
\hline \multicolumn{3}{|c|}{ Interaction effect between sector and school location from ANOVA } \\
\hline \multicolumn{3}{|c|}{ results show that there was significant interaction between gender and } \\
\hline \multicolumn{3}{|c|}{$\begin{array}{l}\text { location in Geometrical thinking. Gender and sector were both combined } \\
\text { as independent variables with Geometrical thinking as dependent variables }\end{array}$} \\
\hline \multirow{2}{*}{\multicolumn{3}{|c|}{$\begin{array}{l}\text { for ANOVA to know the possible interaction effect. For further } \\
\text { elaboration estimated means were graphically represented. Fig. } 1 \text { below }\end{array}$}} \\
\hline & & \\
\hline \multicolumn{3}{|c|}{$\begin{array}{l}\text { shows that rural students of private sector were doing better than female of } \\
\text { public sector while in public sector urban students were found better. }\end{array}$} \\
\hline
\end{tabular}




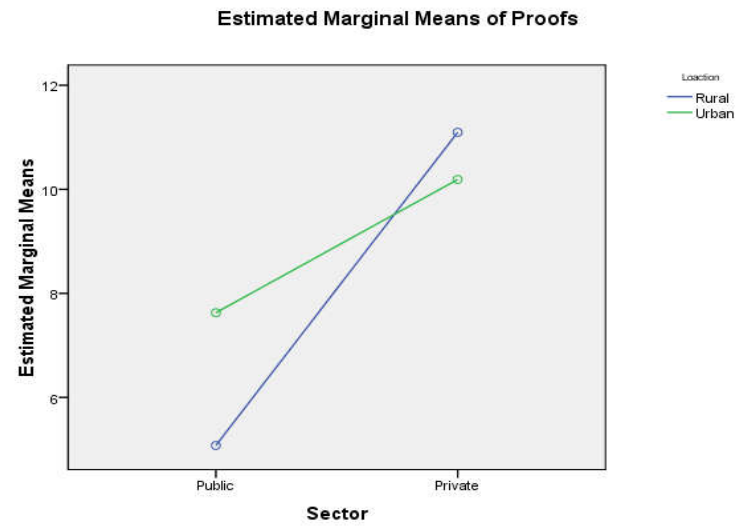

Figure 1: Interaction graph between sector and location

\section{Analysis and Discussion}

Gender wise comparison in mean score of students shows that Males had insignificantly higher scores than females for Geometrical thinking with small effect size. The possible reason of relative higher score by male students is the relatively high expectation of their parents for higher achievement and continuity of further education from male students and availability of coaching facilities in this male dominated and conservative society. On the other hand female students do not have such advantages in this male dominated society. In the same way mean score between rural and urban was also not significant. However in comparison of private/public schools the gap geometrical thinking was wider where students in private performed significantly better than students of public schools. Findings, furthermore, indicate that there was significant interaction effect between location and school sector and Geometrical thinking. Rural students of private school were doing better than urban students of public schools. On the other hand contrasting results was found in case of rural students where urban students in private schools did well in Geometrical thinking. Better score for urban students in private sectors in comparison to rural students of public school is consistent with $t$-test analysis and can be attributed to teachers' availability, effective supervision in private schools. Also rural students mostly comes from low income families and are spending most of the time helping their parents in daily life and thus have less time for study.

Similar study can be conducted on different level with new tools suitable for their level and also can be better conducted using tools that involve diagrammatic reasoning. 


\section{References}

Alasia, A. (2003). Rural and small town Canada analysis. Bulletin Catalogue, 21-006, 4(5).

Baker, T.L. (1994). Doing social research. New York: McGraw-Hill Inc.

Basey, S. W., Joshua, M.T and Asim, A.E. (2008). Gender differences and Mathematics achievement of rural senior secondary students in cross river state, Nigeria downloaded fromhttp://cvs.gnowledge.org/ episteme3/pro_pdfs/09-bassy-joshua- asim.pdf dated 22-June- 2009

Battista, M. (1990). Spatial visualization and gender difference in high school geometry. Journal for Research in Mathematics Education,21(1), 47-60.

Bell, A. (1976). A study of pupils' proof-explanations in mathematical situations. Educational Studies in Mathematics, 7, 23-40.

Benbolv, C. P., \& Stainly, J. C. (1980). Sex differences in mathematical ability: Fact or artifact? Science, 210, 1262-1264.

Benbow, C. P., \& Stanley, J. C. (1983). Sex differences in mathematical reasoning ability: More facts. Science, 222, 1029-1031

Benbow, C. P. (1982). Consequences in high school and college of sex differences in mathematical reasoning ability: A longitudinal perspective. American Educational Research Journal, 19(4), 598.

Benbow, C.P., Lubinski, D., Shea, D.L., \& Sanjani, H.E. (2000). Sex differences in Mathematical reasoning ability at Age 13: Their Status 20 Years Later. Psycho Geometrical Science, 11(6), 474-480

Benbow, C.P., \& Lola, L. (1990). Cognitive profiles of verbally and Mathematically precociou students: Implications for identification of the gifted Minor. Gifted Child Quarterly, 34, 21.

Bitner-Corvin, Betty, L. (1987). The GALT: A Measure of Geometrical Thinking Ability of 7th through 12th Grade Students. Downloaded [17.06.2009] from ww.eric.ed.gov/ERICDocs/data/ericdocs2sq1/ content_storage_01/0000019b/80/1d/7d/29.pdf

Brandon, P.R., Barbara, J., Newton, \& Hammond, O. W. (1987). Children's Mathematics achievement in Hawaii: Sex differences favoring girls. American Educational Research Journal, 24, 437 
Nyaumwe, L., \& Buzuzi G. (2007). Teachers' Attitudes towards Proof of Mathematical Results in the Secondary School Curriculum: The Case of Zimbabwe. Mathematics Education Research Journal, 19(3), 21-32

Brumbaugh, D, K, \& Rock, D. (20Gl). Teaching secondary mathematics. London; Lawrence Erlbaum Associates.

Hanna, G. (1996). The Role of Proof in Mathematics Education. Joetsu Journal of Mathematics Education, 11, 155-168.

Milton, K. Reeves, H. (2003). From conjecture to proof: exploring patterns and relationships leading to 'proofs'. Proceedings of the $19^{\text {th }}$ Biennial Conference of the Australian Association of Mathematics Teachers, pp (384-386). Brisbane: University of Queensland.

Porteous, k.(1990). What Do Children Really Believe? Educational Studies in Mathematics, 21(6), 589-598

Raniya, T. (2017). Teaching mathematics in Pakistan. Downloaded from https://nation.com.pk/28-Mar-2018/teaching-mathematics-inpakistan.

Wheatley, G. H. (1992). The role of reflection in mathematics learning. Educational Studies in Mathematics, 23(5), 529-541

\section{Citation of this Article:}

Zaman, A., Ghafar, A., Fazal ur Rahman., \& Hussain, I. (2018). Examining performance of geometrical thinking in Mathematics at secondary school level in Pakistan. Pakistan Journal of Education, 35(1), $33-42$.

$\begin{array}{cc}\text { Received on: August } & 10,2017 \\ \text { Revised on: January } & 10,2018 \\ \text { Accepted on: March } & 22,2018\end{array}$

